\title{
Article
}

\section{Flame retardants in UK furniture increase smoke toxicity more than they reduce fire growth rate}

Mckenna, Sean Thomas, Birtles, Robert, Dickens, Kathryn, Walker, Richard George, Spearpoint, Michael J, Stec, Anna A and Hull, T Richard

Available at http://clok.uclan.ac.uk/21412/

Mckenna, Sean Thomas, Birtles, Robert, Dickens, Kathryn, Walker, Richard George, Spearpoint, Michael J, Stec, Anna A ORCID: 0000-0002-6861-0468 and Hull, T Richard ORCID: 0000-0002-7970-4208 (2018) Flame retardants in UK furniture increase smoke toxicity more than they reduce fire growth rate. Chemosphere, 196 . pp. 429-439. ISSN 0045-6535

It is advisable to refer to the publisher's version if you intend to cite from the work. http://dx.doi.org/10.1016/j.chemosphere.2017.12.017

For more information about UCLan's research in this area go to

http://www.uclan.ac.uk/researchgroups/ and search for <name of research Group>.

For information about Research generally at UCLan please go to http://www.uclan.ac.uk/research/

All outputs in CLoK are protected by Intellectual Property Rights law, including Copyright law. Copyright, IPR and Moral Rights for the works on this site are retained by the individual authors and/or other copyright owners. Terms and conditions for use of this material are defined in the policies page. 


\section{Flame retardants in UK furniture increase smoke toxicity more than they reduce fire growth rate}

Sean McKenna ${ }^{1}$, Robert Birtles ${ }^{1,2}$, Kathryn Dickens ${ }^{1}$, Richard Walker ${ }^{1,3}$, Michael Spearpoint ${ }^{4,5}$, Anna A Stec $^{1}$ and T Richard Hull ${ }^{1 *}$.

1. Centre for Fire and Hazard Science, University of Central Lancashire, Preston, PR1 2HE, UK

2. Greater Manchester Fire and Rescue Service, Manchester, M4 5HU, UK

3. West Midlands Fire Service Headquarters, 99 Vauxhall Road, Birmingham B7 4HW, UK

4. Department of Civil and Natural Resources Engineering, University of Canterbury, Christchurch 8140, New Zealand

5. Olsson Fire and Risk, Manchester, M4 6WX, UK

*Corresponding author: trhull@uclan.ac.uk

\section{Abstract}

This paper uses fire statistics to show the importance of fire toxicity on fire deaths and injuries, and the importance of upholstered furniture and bedding on fatalities from unwanted fires. The aim was to compare the fire hazards (fire growth and smoke toxicity) using different upholstery materials. Four compositions of sofa-bed were compared: three meeting UK Furniture Flammability Regulations (FFR), and one using materials without flame retardants intended for the mainland European market. Two of the UK sofa-beds relied on chemical flame retardants to meet the FFR, the third used natural materials and a technical weave in order to pass the test. Each composition was tested in the bench-scale cone calorimeter (ISO 5660) and burnt as a whole sofa-bed in a sofa configuration in a $3.4 \times 2.25 \times 2.4 \mathrm{~m}^{3}$ test room. All of the sofas were ignited with a No. 7 wood crib; 
the temperatures and yields of toxic products are reported. The sofa-beds containing flame retardants burnt somewhat more slowly than the non-flame retarded EU sofa-bed, but in doing so produced significantly greater quantities of the main fire toxicants, carbon monoxide and hydrogen cyanide. Assessment of the effluents' potential to incapacitate and kill is provided showing the two UK flame retardant sofa-beds to be the most dangerous, followed by the sofa-bed made with European materials. The UK sofa-bed made only from natural materials (Cottonsafe ${ }^{\circledR}$ ) burnt very slowly and produced very low concentrations of toxic gases. Including fire toxicity in the FFRwould reduce chemical flame retardants and improve fire safety.

\section{Introduction}

\section{Fire statistics}

Fire deaths in the UK showed a dramatic increase from 1955 until the mid-1980s (Figure 1) $)^{1}$. It has been generally accepted that the extra deaths resulted from the increased flammability and smoke toxicity of synthetic polymers, which became widely available in the 1970 s and 1980 s, particularly in domestic furnishings. The greatest change over this period was the replacement of natural materials, such as horsehair and cotton, with flexible polyurethane foam (PUF) as fillings in upholstered furniture. This change resulted in: increased ignitability and fire growth (PUF is a better insulator than cotton or horsehair, so a smaller heat source will cause ignition and the fire will grow quickly because less heat is lost); more dense smoke impeding escape (from the aromatic structures in PUF); and greater smoke toxicity (the burning PUF produces large quantities of the two asphyxiants, carbon monoxide $(\mathrm{CO})$ and hydrogen cyanide $(\mathrm{HCN}))^{2,3}$. In the UK, the Furniture and Furnishings (Fire) (Safety) Regulations were introduced in 1988 requiring all domestic upholstered furniture to meet requirements for lower flammability, specified in BS $5852^{4}$ (as modified by the Schedules to the Regulations), and making it illegal to sell non-compliant furniture, new or secondhand. The fabric covering domestic upholstered furniture must pass the cigarette and match 
ignition tests. Foam and composite fillings must also be resistant to ignition from the "No. 5 wood crib" specified in BS 5852 (as modified).

The UK is currently consulting on a revision to the furniture flammability regulations, for a number of reasons, which include:

- The current test methods have been in place for nearly 30 years, during which time manufacturing materials and processes have radically changed. Furniture manufacturers have optimised their fabrics and fillings to pass the test, with less regard as to how the finished furniture may behave when on fire. For example, modern furniture often incorporates a non-woven polyester "comfort layer" between the fabric and foam, but this makes the fabric more vulnerable to ignition in the actual furniture than in the test.

- The test protocol requires fabrics to be tested on non-compliant foam without flame retardants, as found in furniture before the Regulations were implemented. Components identified in the 1980s need to be tested, but modern furniture may also contain a polyester comfort layer (as above), along with flammable materials such as cardboard, elastic, hessian, thermoplastics etc., which are not included in the current test, but contribute to the burning behaviour of the furniture.

Both the existing and proposed requirements can be met by using less flammable materials, or by the incorporation of flame retardants. Flame retardants offered the most cost effective solution, and allowed manufacturers more flexibility in choice of materials and design. In a report commissioned by the flame retardant industry ${ }^{5}$, and a subsequent report for the UK government ${ }^{6}$, it was argued that "the introduction of fire-safe furniture [in the UK] from 1988 onwards is estimated to have resulted in at least $50 \%$ of the estimated 2002 savings in injuries and domestic fire deaths", the other $50 \%$ being attributed to low cost smoke detectors. Factors such as changes in cigarette smoking habits, the change from exposed flame heating sources and a general improvement in standard of living were not considered ${ }^{7}$. 
New Zealand is a country comparable to the UK in many ways, but where there is no requirement for domestic furniture to be below particular flammability limits. New Zealand's fire death rate shown alongside the UK's in Figure $1^{8}$. It is evident that despite the greater statistical fluctuations from New Zealand's smaller population, the decrease in fire death rate is comparable to that in the UK. A detailed study produced for the European Commission ${ }^{9}$ on the risks and benefits of adding fire retardants to furniture, analysed the fire fatality data from individual European countries with different levels of flammability regulation. While the study acknowledged the difficulty in comparing statistics from different countries, it concluded that "in some instances, drops in the number of fire deaths coincide with the introduction of non-flammability requirements for domestic consumer products. In other instances, however, there is no change in the on-going trend of fire deaths. This suggests that these numbers do not reflect the stringency of non-flammability requirements, respectively that non-flammability requirements do not visibly decrease the number of fire deaths."

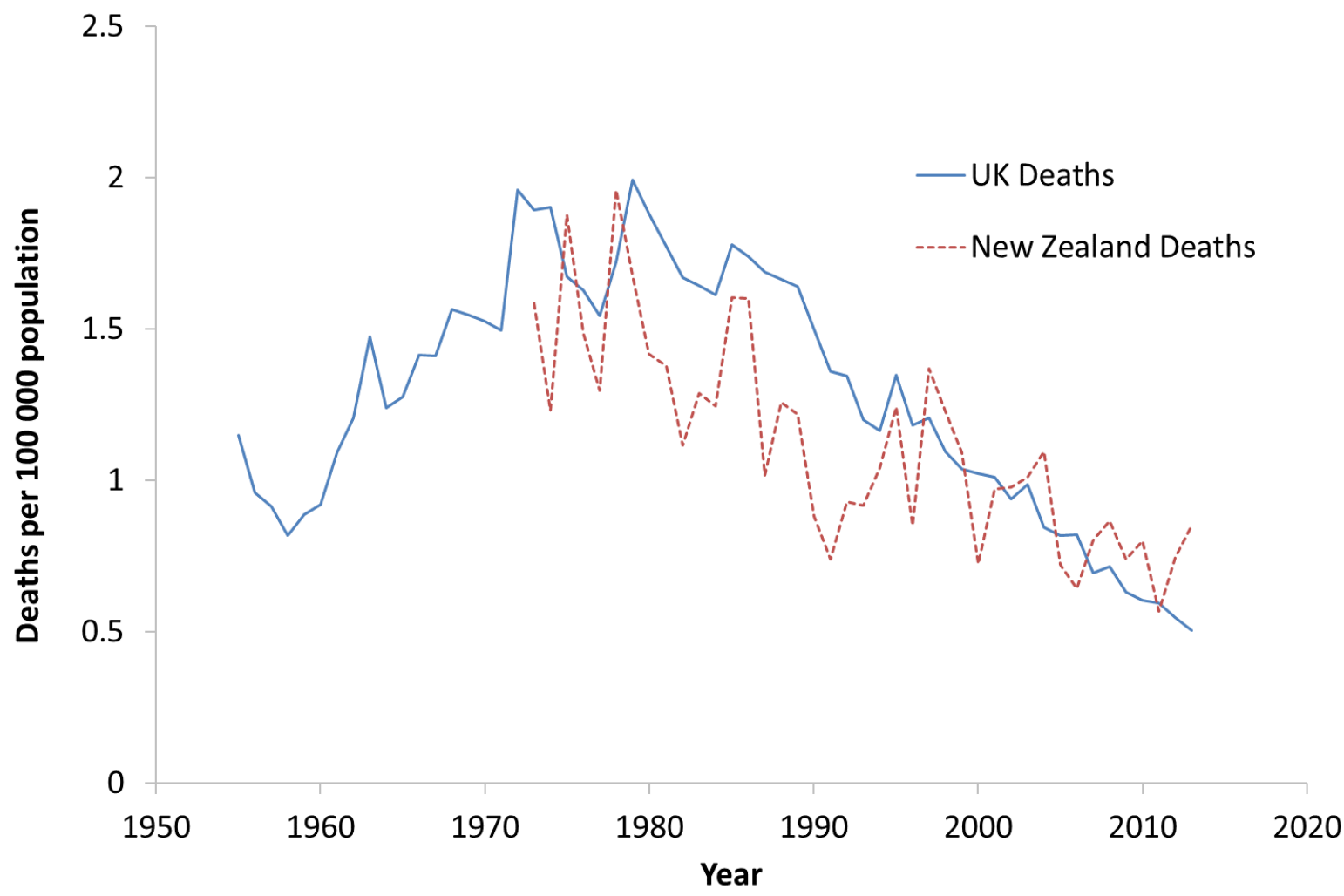

Figure 1 Fire deaths per 100000 population in UK $K^{1}$ (with furniture flammability regulations) and in New Zealand ${ }^{8}$ (where there are no domestic furniture flammability regulations). 
Further analysis of the UK fire statistics for the period $2009-2014$ shows that $77 \%$ of fire fatalities occur in dwellings ${ }^{10}$. These have been broken down by location within the dwelling in Table 1. Although only $12.6 \%$ of fires occur in bedrooms, living rooms and dining rooms, these account for $71.2 \%$ of the fatalities, with a much higher fatality rate. Since most upholstered furniture is located in these rooms, this underlines its importance in fire fatalities (although in fatal fires, which are usually fully developed, reliable identification of the first item ignited is often impossible). The time series data from 1955 to 2013 (Figure 2 and Figure 3) show an increasing proportion of fire deaths resulting from inhalation of toxic smoke ${ }^{1,2}$. Indeed, since 1998 the majority of fire deaths, and since 1991, the majority of fire injuries have resulted from the inhalation of toxic smoke. Explaining these increases is one of the goals of the current study.

Table 1 Proportion of dwelling fires, fire fatalities and fatality rate for UK fires from 2009-2014 ${ }^{1}$

\begin{tabular}{|l|c|c|c|}
\hline Location within dwelling & No. of fires \% & Fatalities \% & Fatality rate per $\mathbf{1 0 0 0}$ fires \\
\hline Kitchen & 42.7 & 18.0 & 1.9 \\
\hline Bed/living/dining room & 12.6 & 71.2 & 25.2 \\
\hline Other & 44.7 & 10.8 & 1.1 \\
\hline
\end{tabular}




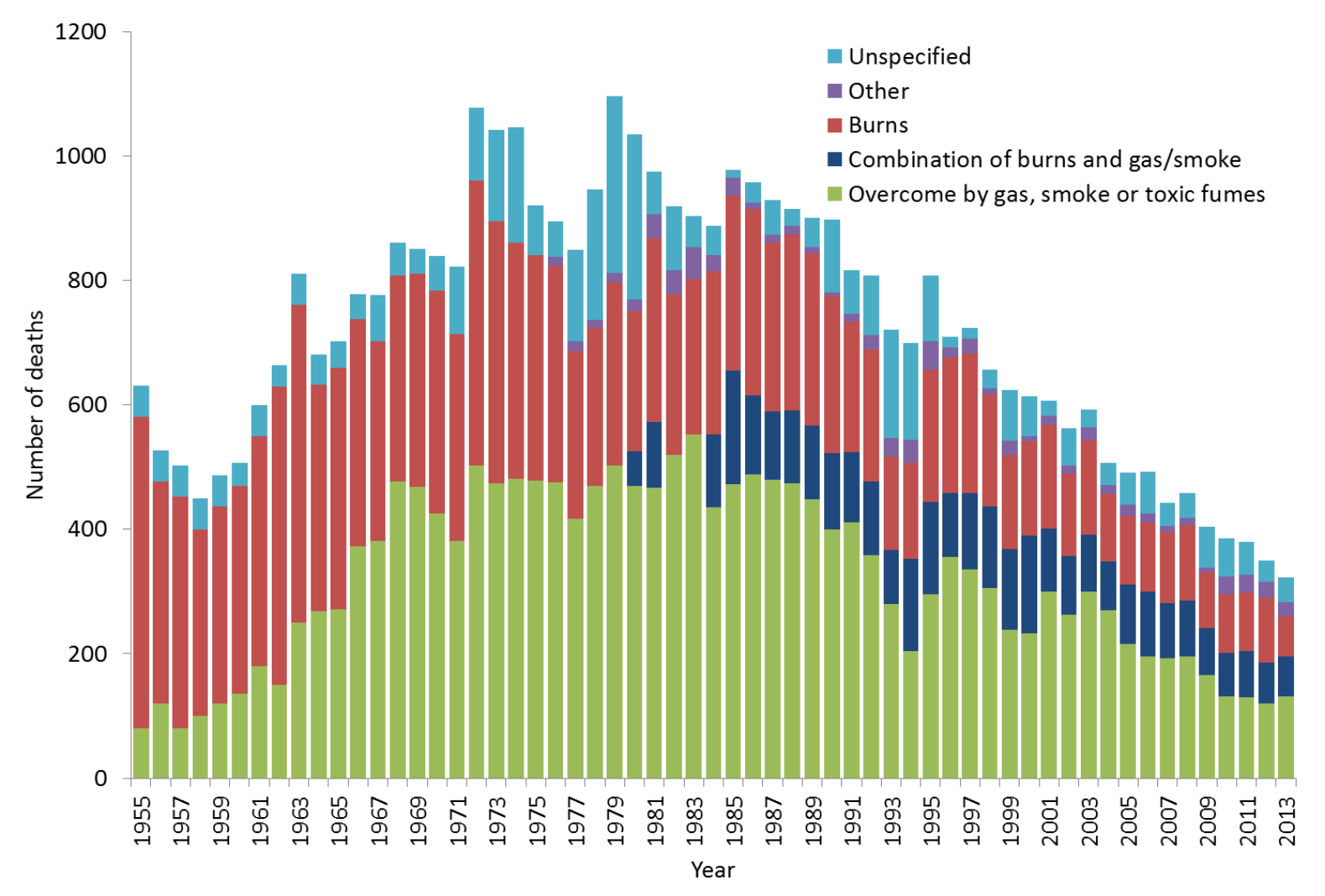

Figure 2 Causes of UK fire deaths from 1955 to 2013 (data taken from refs 1 and 2).

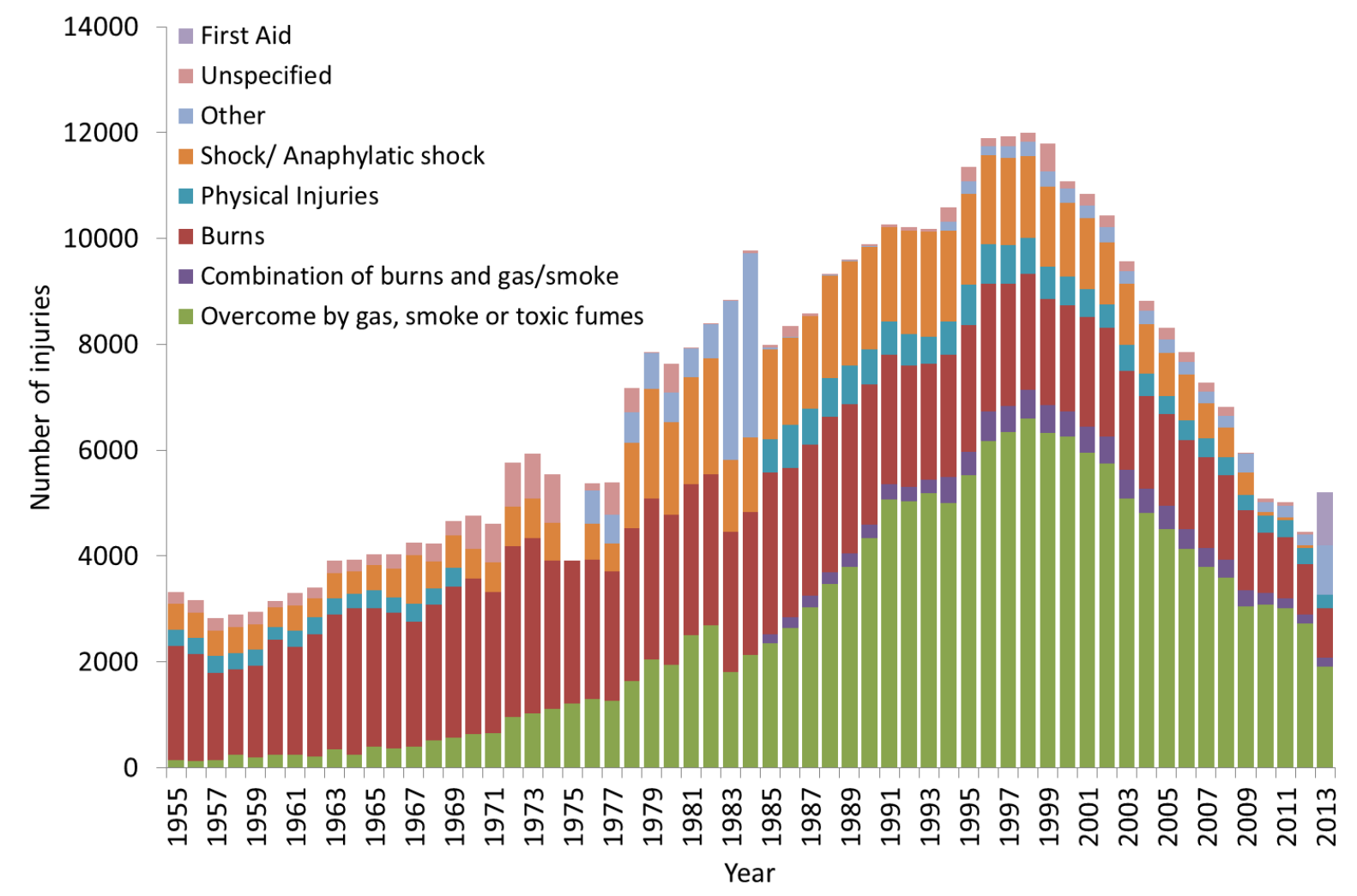

Figure 3 Nature of UK fire injuries from 1955 to 2013 (data taken from refs 1 and 2). 
Despite being recognised as a major cause of death, and a major cause of injury, there has never been a requirement to assess the toxicity of burning furniture in the UK, outside the mass transport industries. It has been argued that while escape is possible from a house or apartment, it is unreasonable to expect escape from a burning train, ship or aeroplane. This clearly has implications for those unable to escape: for example through disability, or living in high-rise apartments. It has also been argued that if ignition could be prevented, that would avoid the more costly process of quantifying fire toxicity. The fact that upholstered furniture fires still cause most UK fire deaths shows that the furniture flammability regulations are not effective in eliminating these deaths ${ }^{1,10,2}$. A large number of studies ${ }^{11,12,13,14,15,16,17}$ have pointed to the toxic and ecotoxic effects of flame retardants, which have been reviewed elsewhere ${ }^{18}$. Moreover, the UK has been shown to have the highest levels of flame retardants in household dust, presumably originating from the treatments applied to upholstered furniture ${ }^{19,20}$. This paper contributes to the assessment of the benefits and risks of flame retardant usage by including the effects of flame retardants on the smoke toxicity so that a scientifically derived balance can be achieved.

\section{Toxic Potency of Fire Effluent}

When the higher fire toxicity of synthetic polymers, and the upholstered furniture made from them, first became apparent in the 1970s, this was investigated by exposing laboratory animals to fire effluents. This led to detailed correlations relating the toxicant concentrations to lethality or incapacitation, generally using additive models to predict the effect of multiple toxicants on animal subjects, which could then be extrapolated to humans ${ }^{21,22}$.

Death or incapacitation may be predicted by quantifying the fire effluents using chemical analysis in different fire conditions. Lethality may be predicted using equations, based on rat lethality data, from ISO $13344^{23}$. Incapacitation (the inability to effect one's own escape) may be predicted using methodology and consensus estimate data in ISO $13571^{24}$. 
The effect of a fire effluent can be expressed as a Fractional Effective Dose (FED), based on its chemical composition. An FED equal to one indicates that the effluent will be effective in causing incapacitation or death to $50 \%$ of the exposed population. For incapacitation, ISO 13571 considers the four major hazards which may prevent escape (asphyxiant gases, irritant gases, heat and visible smoke obscuration). It includes a separate calculation for prediction of incapacitation by each of the four hazards for humans exposed to fire effluents. Equation 1 allows estimation of when the asphyxiants $\mathrm{CO}$ and $\mathrm{HCN}$ will cause incapacitation.

$\mathrm{FED}=\sum_{t_{1}}^{t_{2}} \frac{[\mathrm{CO}]}{35000} \Delta t+\sum_{t_{1}}^{t_{2}} \frac{[H C N]^{2.36}}{1.2 \times 10^{6}} \Delta t$

Gas concentrations in [ ] are expressed in $\mu \mathrm{L} \mathrm{L}^{-1}$ or ppm; time, $\mathrm{t}$, is in min.

\section{Equation $\mathbf{1}^{24}$}

For lethality, this can be calculated using Equation 2 for a 30 minute exposure, using the ratio of each toxicant concentration to its lethal concentration $\left(\mathrm{LC}_{50}\right)$. Since carbon dioxide $\left(\mathrm{CO}_{2}\right)$ increases the respiration rate, Equation 1 uses a multiplication factor for $\mathrm{CO}_{2}$-driven hyperventilation, $\mathrm{V}_{\mathrm{CO}_{2}}$, to increase the FED contribution from all the toxic species, and incorporates an acidosis factor, A, to account for toxicity of $\mathrm{CO}_{2}$ in its own right ${ }^{23}$.

$$
\begin{aligned}
\mathrm{FED} & =\left\{\frac{[\mathrm{CO}]}{\mathrm{LC}_{50, \mathrm{CO}}}+\frac{[\mathrm{HCN}]}{\mathrm{LC}_{50, \mathrm{HCN}}}+\frac{[\mathrm{HCl}]}{\mathrm{LC}_{50, \mathrm{HCl}}}+\frac{\left[\mathrm{NO}_{2}\right]}{\mathrm{LC}_{50, \mathrm{NO}_{2}}}+\ldots .+ \text { organics }\right\} \times \mathrm{V}_{\mathrm{CO}_{2}}+\mathrm{A}+\frac{21-\left[\mathrm{O}_{2}\right]}{21-5.4} \\
\mathrm{~V}_{\mathrm{CO}_{2}} & =1+\frac{\exp \left(0.14\left[\mathrm{CO}_{2}\right]\right)-1}{2}
\end{aligned}
$$

A is an acidosis factor equal to $\left[\mathrm{CO}_{2}\right] \times 0.05$.

Gas concentrations are expressed in vol\%, or the same units as the corresponding $\mathrm{LC}_{50}$ value.

\section{Equation $\mathbf{2}^{23}$}




\section{Influence of FRs on fire toxicity}

Gas phase flame retardants, such as those based on organohalogen or organophosphorus compounds, interfere with the free radical reactions responsible for flaming combustion ${ }^{25}$. This results in incomplete oxidation of vapour phase fuel molecules, leading to higher yields of all products of incomplete combustion ${ }^{26}$. These are all more toxic than the cleaner products of complete combustion (carbon dioxide and water), and include carbon monoxide, hydrogen cyanide, hydrocarbons, oxygenated organics (including organoirritants, such as acrolein and formaldehyde) and larger cyclic molecules such as polycyclic aromatic hydrocarbons and soot particulates. Fire toxicity increases as combustion becomes more incomplete, which can arise from chemical quenching (for example by gas phase flame retardants), insufficient heat (for example during smouldering), or when the fire becomes ventilation controlled, and there is insufficient oxygen for complete combustion ${ }^{27}$. Recently it has been shown that the phosphorus flame retardants which act predominantly in the gas phase have a smaller influence on increasing the $\mathrm{CO}$ and $\mathrm{HCN}$ yields than the corresponding brominated flame retardant ${ }^{28}$.

\section{Influence of fire conditions on toxic product yields.}

Burning behaviour and toxic product yield depend most strongly on a few of factors. Material composition, temperature and oxygen concentration are normally the most important ${ }^{29,30}$. As fires grow, they become ventilation controlled, and fires in buildings rapidly change from well-ventilated to under-ventilated. Data from large scale fires ${ }^{31,32}$ in enclosures show much higher levels of both asphyxiant gases $\mathrm{CO}$ and $\mathrm{HCN}$ under conditions of developed flaming than those from small, wellventilated tests, such as the cone calorimeter ${ }^{33}$ (ISO 5660). For a particular material, under different fire conditions, the HCN yield has been shown to rise proportionately with the $\mathrm{CO}$ yield $\mathrm{d}^{34,35,36}$. 


\section{Background to the current study}

The current study uses a simple sofa-bed (a double mattress which folds to make a sofa) on a steel test frame, instead of the normal wooden frame to investigate the fire toxicity of different fabricfilling combinations. Four mattress formulations have been tested in duplicate, using commercially available fabrics and fillings: UK sourced fire retardant fabric, non-woven polyester comfort layer and combustion-modified foam (UKFR); a fire retardant fabric meeting UK furniture flammability regulations sourced in China (ChFR) on the same comfort layer and foam as with the UKFR sample; fabric and foam for the mainland European market (where there are no furniture flammability regulations) (EUMat); and a technically woven cover fabric, including cotton and wool with wool, cotton and polyester fillings, specially designed to meet the UK furniture flammability regulations without the use of chemical flame retardants (sold under the trade name Cottonsafe ${ }^{\circledR}$ )(FRfreeCS).

The flammability of the fabric-filling combinations were tested in the laboratory using a cone calorimeter, and using large-scale burns, in a modified steel shipping container with restricted ventilation, to represent a normal UK living room. The burning behaviour and toxic gas concentration were used to quantify the fire hazards of each sofa-bed.

Three effects of flame retardants on fire safety can be identified: changing the ignitability; changing the rate of fire growth; and changing the toxicity of the smoke. This study does not address the first effect, because successful ignition suppression by flame retardants is rarely reported, and large dwelling fires frequently involve upholstered furniture, whether or not it was the first item ignited. Without ignition suppression data, it is very difficult to make an objective statement about the benefits of flame retardants. The study specifically compares the fire growth rate and fire smoke toxicity of the four furniture-fabric constructions outlined. 


\section{Experimental}

\section{Materials}

Two mattresses of each of the specifications shown in Table 2 were made especially for the tests by Cottonsafe ${ }^{\circledR}$ Natural Mattress, Devon, UK, together with a single steel frame. Each mattress had dimensions $1.9 \mathrm{~m} \times 1.5 \mathrm{~m} \times 0.15 \mathrm{~m}$. Figure 4 shows the mattress in the sofa configuration as used in these tests. The same materials were used to prepare filling/fabric test samples for the bench-scale cone calorimetry tests.

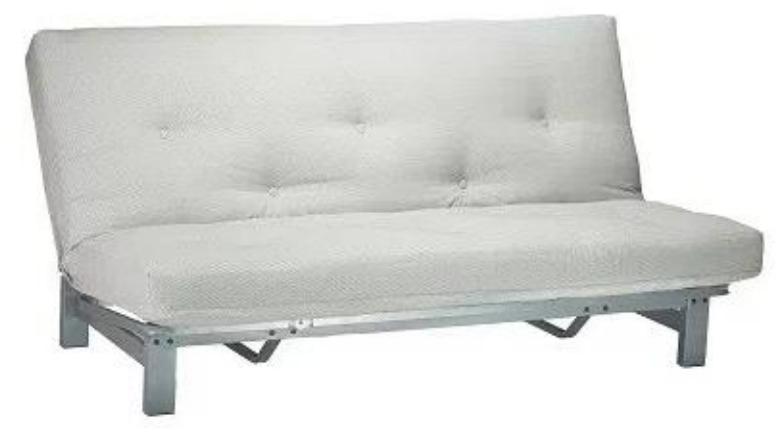

Figure 4 Folded mattress as sofa, shown on normal wooden frame ${ }^{37}$.

Table 2 Mattress compositions and identification

\begin{tabular}{|c|c|}
\hline Sample ID & Construction \\
\hline UKFR & $\begin{array}{l}\text { Combustion modified flexible polyurethane foam; polyester comfort } \\
\text { layer; fire retardant fabric cover (sourced from the UK). }\end{array}$ \\
\hline ChFR & $\begin{array}{l}\text { Combustion modified flexible polyurethane foam; polyester comfort } \\
\text { layer; fire retardant fabric cover (sourced from China). }\end{array}$ \\
\hline EUMat & $\begin{array}{l}\text { Flexible polyurethane foam; polyester comfort layer; untreated fabric } \\
\text { cover (sourced from Europe). }\end{array}$ \\
\hline FRfreeCS & $\begin{array}{l}\text { Polycotton pad surrounded by woollen comfort layer; technically woven } \\
\text { cotton and wool cover. No chemical fire retardant treatments (made in } \\
\text { the UK). }\end{array}$ \\
\hline
\end{tabular}




\section{Analysis for Flame Retardants}

No detailed information on the fabric formulation was provided by the suppliers, so the fabric samples were sent for independent analysis at the specialist facility at Duke University, NC, US. They positively identified decabromodiphenyl ether (BDE-209) and decabromodiphenyl ethane (DBDPE) in the UKFR fabric. This was surprising, because BDE-209 has been listed by the Stockholm convention, and although its "sunset date" in Europe is March 2018, it is thought to have been largely withdrawn from the market. The ChFR fabric was found to contain tris-(chloropropyl) phosphate (TCIPP), and decabromodiphenyl ethane (DBDPE).

Individual materials were also subject to in-house elemental analysis using CHNS (Thermo Scientific Flash 2000 Organic Elemental Analyser), SEM-EDAX (FEI Quanta 200), and X-Ray fluorescence (Bruker Trace IV-SD handheld XRF) at both $25 \mathrm{keV}$ and $40 \mathrm{keV}$. Foam/filling samples containing heteroelements were subject to solvent extraction in hexane $(4 \mathrm{~h})$ followed by direct injection mass spectrometry (MS) (Finnigan LCQ Advantage Max) and pyrolysis GC-MS (CDS analytical pyroprobe 5000 series connected to a Trace GC ultra DSQ II) to identify flame retardants.

\section{Cone Calorimetry}

The cone calorimeter, described in ISO $5660^{33}$, is a standard method for burning small samples under a constant heat flux, with ignition piloted by an electronic spark, under well-ventilated conditions. The bench-scale composite test samples were prepared to quantify their ignition and burning behaviour. The test pieces consisted of the bulk pad ( $90 \mathrm{~mm} \times 90 \mathrm{~mm} \times 15 \mathrm{~mm}$ thick), comfort layer ( $90 \mathrm{~mm} \times 90 \mathrm{~mm} \times 7 \mathrm{~mm}$ thick) and fabric cover layer wrapped around the sample ( $300 \mathrm{~mm}$ $\times 300 \mathrm{~mm}$ ). The samples were stapled to create a pillow-like sample with a total thickness of $\sim 25 \mathrm{~mm}$. Aluminium foil was wrapped around the sides and underneath the sample to prevent fuel loss as molten drips. The composite test samples were tested in a Govmark cone calorimeter at 
$35 \mathrm{~kW} \mathrm{~m}^{-2}$ incident heat flux with upper sample retaining frame, in accordance with ISO 5660, running each sample in triplicate.

In addition to the standard protocol, gas analysis was undertaken to quantify the yield of HCN from each sample during the cone calorimeter test, collecting effluent in metered bubblers for subsequent analysis, carried out in duplicate. In both cone calorimetry and large scale tests the HCN was quantified using the Chloramine T method described in ISO $19701^{38}$.

\section{Large Scale Tests}

The sofa-beds were burnt in a $3.4 \mathrm{~m} \times 2.25 \mathrm{~m} \times 2.4 \mathrm{~m}$ test room made by modifying a steel shipping container, located outside (Figure 5). An outlet vent (1040 mm $\times 200 \mathrm{~mm}$ ) was cut into one of the steel walls $600 \mathrm{~mm}$ from the top of the container. The entrance was closed with a plasterboard wall supported by timber framing, containing a ventilation inlet $(323 \mathrm{~mm} \times 323 \mathrm{~mm}$ ) located $300 \mathrm{~mm}$ above floor level, on the opposite side of the container to the outlet vent. The outlet was twice the area of the inlet so that only cool air flowed into the container through the inlet, and only hot effluent left through the outlet. A door was also built into this wall to allow test mattresses to be changed and samples ignited. The floor was wooden, and the sofa-bed was placed on a sheet of plasterboard.

A thermocouple tree with four K-type thermocouples was placed inside the test room. The thermocouples were situated $0.5 \mathrm{~m}$ above floor level (at a similar height to the crib on the test sample), at $1.1 \mathrm{~m}$, and at $1.6 \mathrm{~m}$ and $2.0 \mathrm{~m}$ (just below and above the outlet vent). This allowed for a temperature profile to be measured inside the container. Two additional thermocouples were placed at the outlet vent to measure the temperature of the smoke plume.

In order to ensure that each mattress ignited first time, a larger, No. 7 crib, containing $125 \mathrm{~g}$ of Scots Pine (Pinus Silvestris), arranged as an open frame to give adequate ventilation, was employed to ensure sustained ignition, since three of the four compositions were supplied as having already 
resisted ignition using the No. 5 wooden crib (containing $17 \mathrm{~g}$ wood). A small piece of lint provided the initial ignition point at the base of the structure. The crib was located centrally on the sofa, at the back of the seat, next to the back rest.

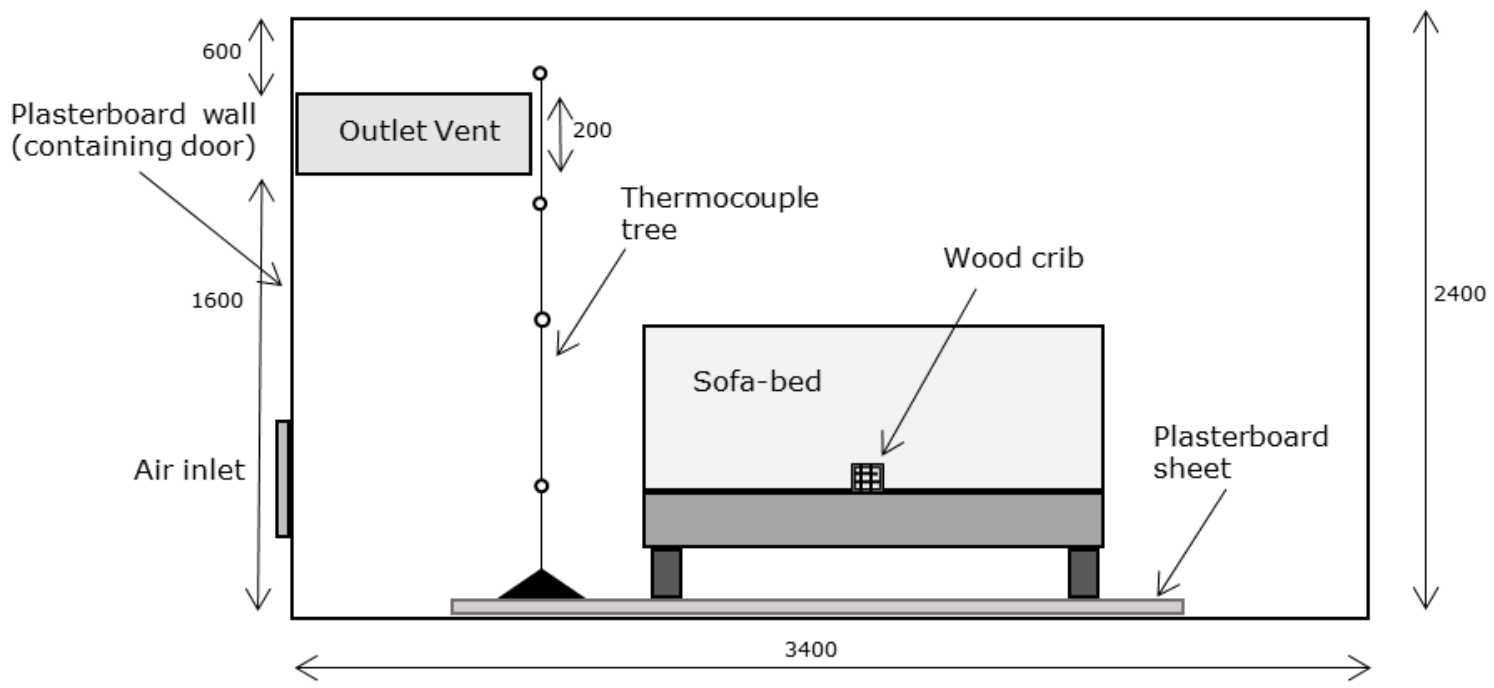

Figure 5 Side view of the test room showing sofa bed, thermocouple tree, and location of inlet and outlet vents (all dimensions in $\mathrm{mm}$ )

\section{Gas sampling}

Field sampling kits had been built in-house for continuous monitoring of $\mathrm{CO}$, carbon dioxide $\left(\mathrm{CO}_{2}\right)$ and oxygen $\left(\mathrm{O}_{2}\right)$, and for quantifying $\mathrm{HCN}$ by bubbling metered volumes of fire effluent through aqueous sodium hydroxide solution $\left(0.1 \mathrm{~mol} \mathrm{dm}^{-3}\right)^{39}$. Up to seven dreschel bottles could be switched into the sampling line sequentially, to quantify seven temporal variations in $\mathrm{HCN}$ concentration.

\section{Experimental protocol}

Gas sampling was switched on and allowed to stabilise. The crib was ignited, the time noted, and the door in the plasterboard wall closed. Ignition was observed through a small viewing port in the plasterboard wall. The tests were allowed to continue until extinction, with the exception of the FRfreeCS mattress, which was extinguished after an hour to fit within the testing schedule. 


\section{Results}

\section{Characterisation of Materials}

The elemental analysis of the materials using CHNS, X-Ray Fluorescence (XRF), and SEM-EDAX is summarised in Table 3.

Table 3 CHNS, XRF and SEM EDAX analysis of fabric, foam and filling.

\begin{tabular}{|c|c|c|c|c|c|c|}
\hline Component & $\mathrm{C} \%$ & H\% & $\mathbf{N} \%$ & S \% & $\begin{array}{l}\text { Oxygen } \\
\text { and other } \\
\text { elements } \\
\%\end{array}$ & $\begin{array}{l}\text { Elements } \\
\text { detected by } \\
\text { EDAX/XRF }\end{array}$ \\
\hline UKFR Fabric & 38.07 & 5.40 & 0.00 & 0 & 56.53 & $\mathrm{O}, \mathrm{Cl}, \mathrm{Br}$ \\
\hline UK/Ch Foam & 52.53 & 7.27 & 12.88 & 0 & 27.32 & $\mathrm{O}, \mathrm{P}, \mathrm{Cl}$ \\
\hline UK/Ch/EU Polyester & 61.09 & 4.26 & 0.13 & 0 & 34.51 & $\mathrm{O}$ \\
\hline ChFR Fabric & 52.86 & 4.18 & 0.00 & 0 & 42.96 & $\mathrm{O}, \mathrm{Cl}, \mathrm{Br}, \mathrm{Sb}$ \\
\hline EUMat Fabric & 41.71 & 6.28 & 0.04 & 0 & 51.97 & $\mathrm{O}$ \\
\hline EUMat Foam & 57.23 & 5.87 & 5.51 & 0 & 31.39 & $\mathrm{O}$ \\
\hline FRfreeCS Fabric & 41.31 & 6.14 & 0.07 & 0 & 52.48 & 0 \\
\hline FRfreeCS wool & 44.44 & 6.93 & 13.71 & 2.27 & 32.64 & $\mathrm{O}, \mathrm{S}$ \\
\hline $\begin{array}{l}\text { FRfreeCS } \\
\text { Polycotton }\end{array}$ & 52.25 & 5.10 & 0.00 & 0 & 42.66 & $\mathrm{O}$ \\
\hline
\end{tabular}

The elemental analysis showed the presence of phosphorus and chlorine in the foam, and in the UK and China-sourced fabrics. Solvent extraction, followed by direct injection mass spectrometry indicated the presence of tris(1-chloro-2-propyl) phosphate (TCPP m.w 327.56, detected $\mathrm{m} / \mathrm{z} 327.0$ ). Further analysis using pyrolysis-GCMS detected TCPP (68.4\%) and two isomers, bis(1-chloro-2propyl)-2-chloropropyl phosphate (26.3\%) and bis(2-chloropropyl)-1-chloro-2-propyl phosphate (5.3\%). This ratio of TCPP isomers is similar to the commonly sold compositions Fyrol PCF ${ }^{\circledR}$ and 
Antiblaze $80^{\circledR}$, supporting the conclusion that the flame retardant in the combustion modified polyurethane foam is TCIPP. The ChFR fabric also contained antimony (presumably as $\mathrm{Sb}_{2} \mathrm{O}_{3}$ ), which would function as a synergist with the brominated flame retardant. Thus gas phase flame inhibitors were present in both the foam and the fabric of both the UKFR and ChFR mattresses. No evidence of flame retardants was found in the EUMat fabric or foam.

\section{Cone Calorimetry}

All four samples ignited within the first $20 \mathrm{~s}$ of exposure to the cone heater and continued to burn for similar times ( $400 \mathrm{~s}$ ), except the UKFR sample, which extinguished much earlier ( $\sim 100 \mathrm{~s})$. A summary of cone calorimetry results is presented in Table 4 and the heat release rate (HRR) curves are presented in Figure 6.

Table 4 Summary data from cone calorimetry on furniture composites at $35 \mathrm{~kW} \mathrm{~m}^{-2}$ incident heat flux (HRR is heat release rate, and PHRR is peak heat release rate).

\begin{tabular}{|c|c|c|c|c|c|c|c|c|c|}
\hline Material & $\begin{array}{l}\text { Sample } \\
\text { mass /g }\end{array}$ & $\begin{array}{l}\text { Mass } \\
\text { loss \% }\end{array}$ & $\begin{array}{l}\text { Mass loss } \\
\text { rate } \\
/ \mathrm{g} \mathrm{m}^{-2} \mathrm{~s}^{-1}\end{array}$ & $\begin{array}{l}\text { Time to } \\
\text { ignition } \\
\text { /s }\end{array}$ & $\begin{array}{l}\text { Total } \\
\text { heat } \\
\text { release } \\
/ \mathrm{MJ} \mathrm{m}^{-2}\end{array}$ & $\begin{array}{l}\text { Peak HRR } \\
/ \mathrm{kW} \mathrm{m}^{-2}\end{array}$ & $\begin{array}{l}\text { Time to } \\
\text { PHRR } \\
\text { /s }\end{array}$ & $\begin{array}{l}\text { CO Yield } \\
\mathrm{g} / \mathrm{g}\end{array}$ & $\begin{array}{l}\mathrm{HCN} \text { Yield } \\
\mathrm{mg} / \mathrm{g}\end{array}$ \\
\hline UKFR & 38.3 & 25.3 & $6.3 \pm 0.05$ & $7.6 \pm 1.9$ & $4.7 \pm 0.15$ & $112.1 \pm 36$ & $24.5 \pm 13$ & $0.062 \pm 0.002$ & $0.42 \pm 0.17$ \\
\hline ChFR & 39.8 & 70.6 & $8.9 \pm 0.3$ & $12.0 \pm 3.1$ & $38.4 \pm 4.8$ & $164.5 \pm 16.7$ & $39.0 \pm 2.8$ & $0.160 \pm 0.009$ & $0.97 \pm 0.24$ \\
\hline EUMat & 34.5 & 73.3 & $5.3 \pm 0.3$ & $5.2 \pm 1.1$ & $45.2 \pm 1.4$ & $212.9 \pm 18.4$ & $47.0 \pm 2.8$ & $0.008 \pm 0.001$ & $0.31 \pm 0.001$ \\
\hline FRfreeCS & 37.0 & 69.3 & $3.6 \pm 0.6$ & $6.8 \pm 0.6$ & $40.9 \pm 2.0$ & $185.7 \pm 4.8$ & $25.5 \pm 0.6$ & $0.015 \pm 0.003$ & $0.09 \pm 0.02$ \\
\hline
\end{tabular}

The UKFR composite ignited around the same time as the samples without flame retardants but had the lowest total heat release of the four samples due to rapid self-extinguishment. The low mass loss shows that most of the polyurethane foam, which made up the bulk of the sample, did not burn under these conditions. It is therefore appropriate that the yields of the two asphyxiants $\mathrm{CO}$ and 
$\mathrm{HCN}$ are presented on a mass-loss basis. The ChFR sample produced the highest yield of CO, followed by the UKFR sample, showing the effect of gas-phase free radical quenchers (like TCIPP, DBDPE and $\mathrm{BDE}-209$ ) that inhibit the conversion of $\mathrm{CO}$ to $\mathrm{CO}_{2}$ by reducing the concentration of the $\mathrm{OH} \cdot$ radica $^{28}$. The $\mathrm{HCN}$ yields, which generally increase in proportion to $\mathrm{CO}$ yields ${ }^{34}$, show the same effect of being enhanced by the presence of a gas-phase flame retardant ${ }^{40}$, but are relatively low, as would be expected from a well-ventilated test.

The ChFR sample suppressed ignition for longer than the other materials, but had a high mass loss and peak HRR (PHRR). The EUMat and FRfreeCS samples showed similar total heat release and mass loss to the ChFR sample, with slightly higher PHRR.

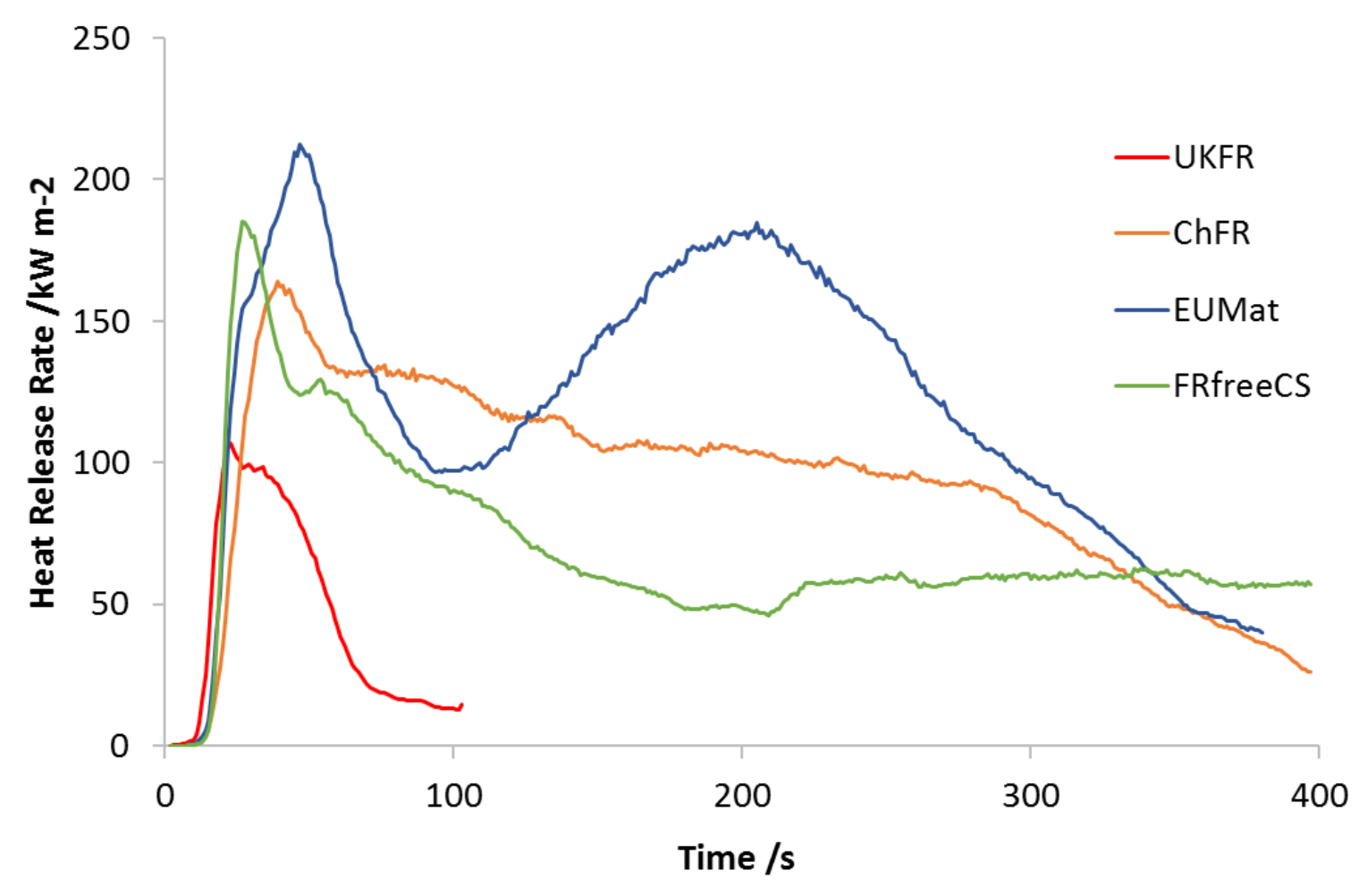

Figure 6 Representative heat release rate curves measured in cone calorimeter at $35 \mathrm{~kW} \mathrm{~m}^{-2}$. 


\section{Large Scale Tests}

\section{Ignition, temperature and mass loss data}

Sustained ignition was observed in all eight tests on the four compositions following application of an ignited No.7 wood crib. Table 5 shows the mass of each mattress before and after the test, the time for the mattress to ignite, and the maximum temperature recorded by the thermocouples in the test room. The mass after the test for FRfreeCS could not be determined as each mattress had been extinguished with copious quantities of water.

Table 5 Mass loss, temperature and time data from the large-scale tests.

\begin{tabular}{|c|c|c|c|c|c|}
\hline Sample & $\begin{array}{l}\text { Mass } \\
\text { /kg }\end{array}$ & $\begin{array}{c}\text { Mass after } \\
\text { test } \\
\text { /kg }\end{array}$ & $\begin{array}{c}\text { Ignition time } \\
\qquad / \mathrm{s}\end{array}$ & $\begin{array}{c}\text { Maximum } \\
\text { temperature } \\
/^{\circ} \mathrm{C}\end{array}$ & $\begin{array}{c}\text { Time of } \\
\text { maximum } \\
\text { temp } \\
\text { /s }\end{array}$ \\
\hline UKFR1 & 12.3 & 2.4 & 297 & 286 & 635 \\
\hline UKFR2 & 12.0 & 2.0 & 131 & 365 & 586 \\
\hline ChFR1 & 12.6 & 2.1 & 525 & 287 & 704 \\
\hline ChFR2 & 12.6 & 4.5 & 297 & 285 & 767 \\
\hline EUMat1 & 11.2 & 0.4 & 128 & 600 & 516 \\
\hline EUMat2 & 11.1 & 0.323 & 212 & 542 & 736 \\
\hline FRfreeCS1 & 21.1 & - & 228 & 220 & 4070 \\
\hline FRfreeCS2 & 21.6 & - & 143 & 171 & 3553 \\
\hline
\end{tabular}


Figure 7 shows the temperature recorded on the highest thermocouple $(2.0 \mathrm{~m})$ for each test. Reasonable reproducibility was obtained for each pair of apparently identical mattresses, despite the different weather conditions and wind directions on the day of each test. The UKFR1 and ChFR1 tests were the only two tests performed on the first day, in significantly windier and wetter conditions; visual observation showed the wind moving the crib flame away from the back of the sofa in the first two tests; they showed longer ignition delay times than the subsequent tests, where calmer, more stable weather conditions prevailed, until the end of the test programme. The EUMat sofa-beds ignited most quickly and reached the highest temperatures, followed by the UKFR then the ChFR sofas.

The FRfreeCS sofas ignited but flaming ceased after 30s, which was followed by smouldering combustion, until they re-ignited at $1200 \mathrm{~s}$ in test 1 and $1730 \mathrm{~s}$ in test 2 . After an hour the temperature in the container was much lower than any of the other tests, when flames were extinguished. Visual observations showed that the majority of the sample had not burned, suggesting that the sofa burning could have continued slowly for some time. 


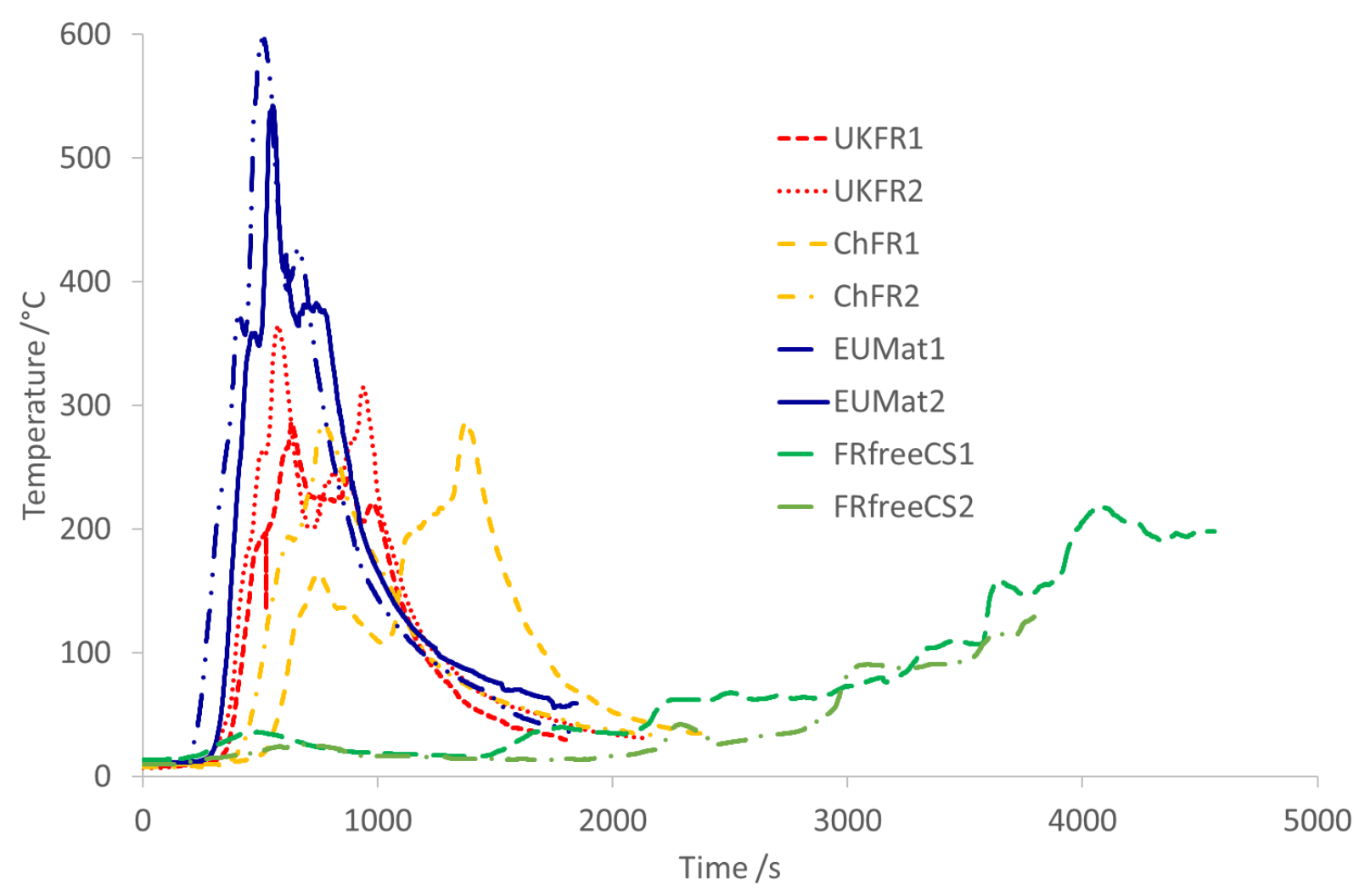

Figure 7 Temperatures at $2 \mathrm{~m}$ thermocouple during large scale tests.

\section{Gas measurements}

$\mathrm{CO}, \mathrm{CO}_{2}$ and $\mathrm{O}_{2}$ concentrations were continuously monitored for each experiment, and $\mathrm{HCN}$ was sampled in bubblers from the outlet vent, using portable gas analysers. Unfortunately, the analysers malfunctioned for the first two tests, UKFR 1 and CHFR 1 , so no replicate data are available for these mattresses.

Figure 8 shows the CO concentrations for each mattress, with the greatest peak in the EUMat1 test, followed by the UKFR2 and EUMat2 tests. ChFR2 showed a later peak of lower intensity, while the FRfreeCS showed very low levels of CO throughout the burn. 


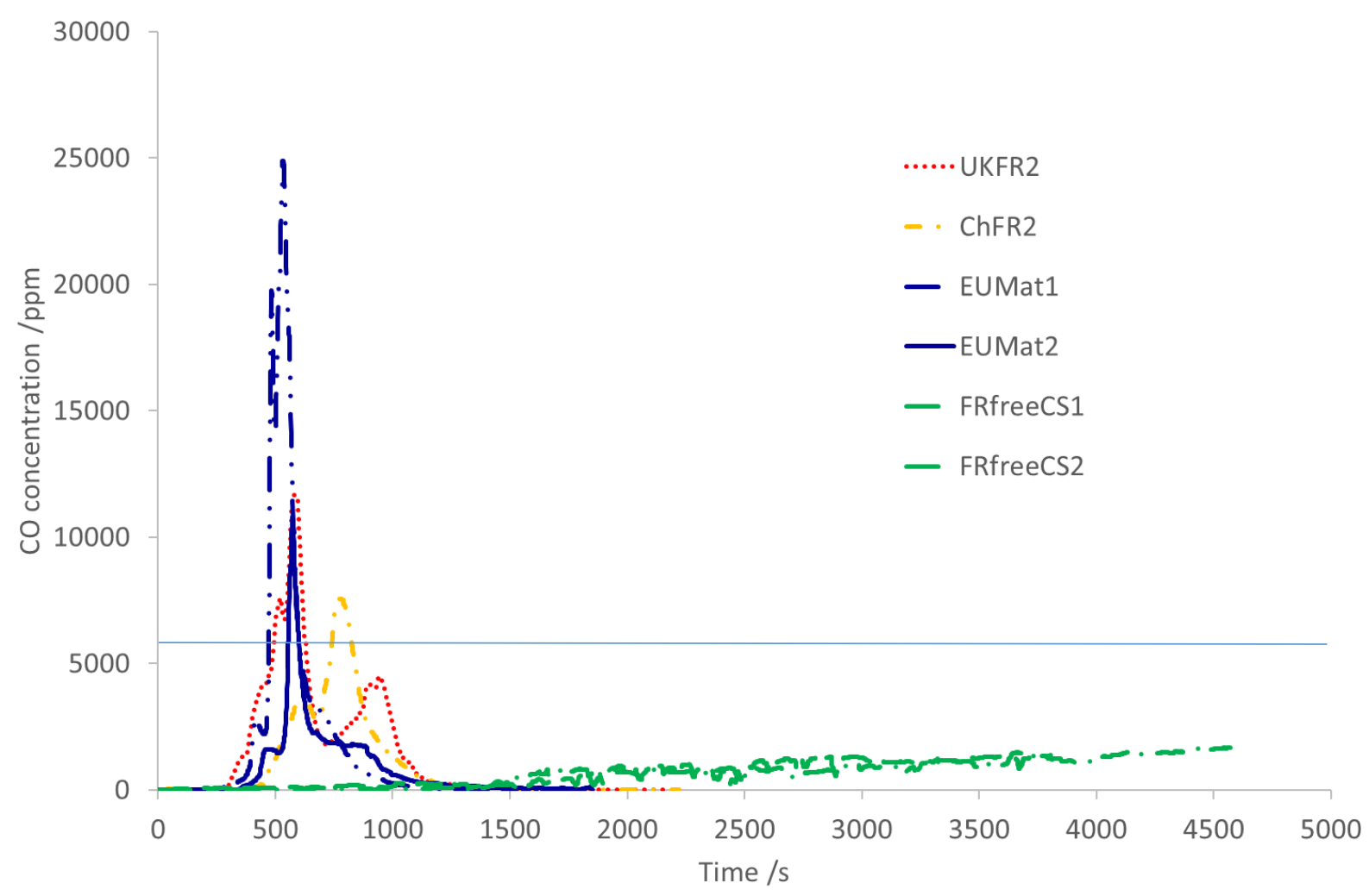

Figure 8 Carbon monoxide concentration (showing $L C_{50}$ for 30 minutes exposure at 5700 ppm from ISO $13344^{23}$ ).

The HCN concentrations, sampled at the outlet, were calculated from the measured concentrations collected in the bubblers for fixed time intervals (typically 3 to $5 \mathrm{~min}$ ). In order to better represent the temporal variation, the $\mathrm{HCN} / \mathrm{CO}$ ratio was determined from the measured values for each mattress, and the CO concentrations multiplied by this ratio to obtain the curves shown in Figure 9, following the methodology described elsewhere ${ }^{35}$. These show the highest peak HCN concentration, of around 800 ppm, for EUMat1 and UKFR2 tests, followed ChFR2. The HCN peak for EUMat2 is very much smaller. The length of the burn for the FRfreeCS meant that bubbler samples were somewhat unevenly spaced, placing greater reliance on extrapolation of CO data. The lack of HCN after $2500 \mathrm{~s}$ is consistent with the cover fabric containing wool (and therefore being a source of $\mathrm{HCN}$ ), while the cotton filling does not produce $\mathrm{HCN}$. 


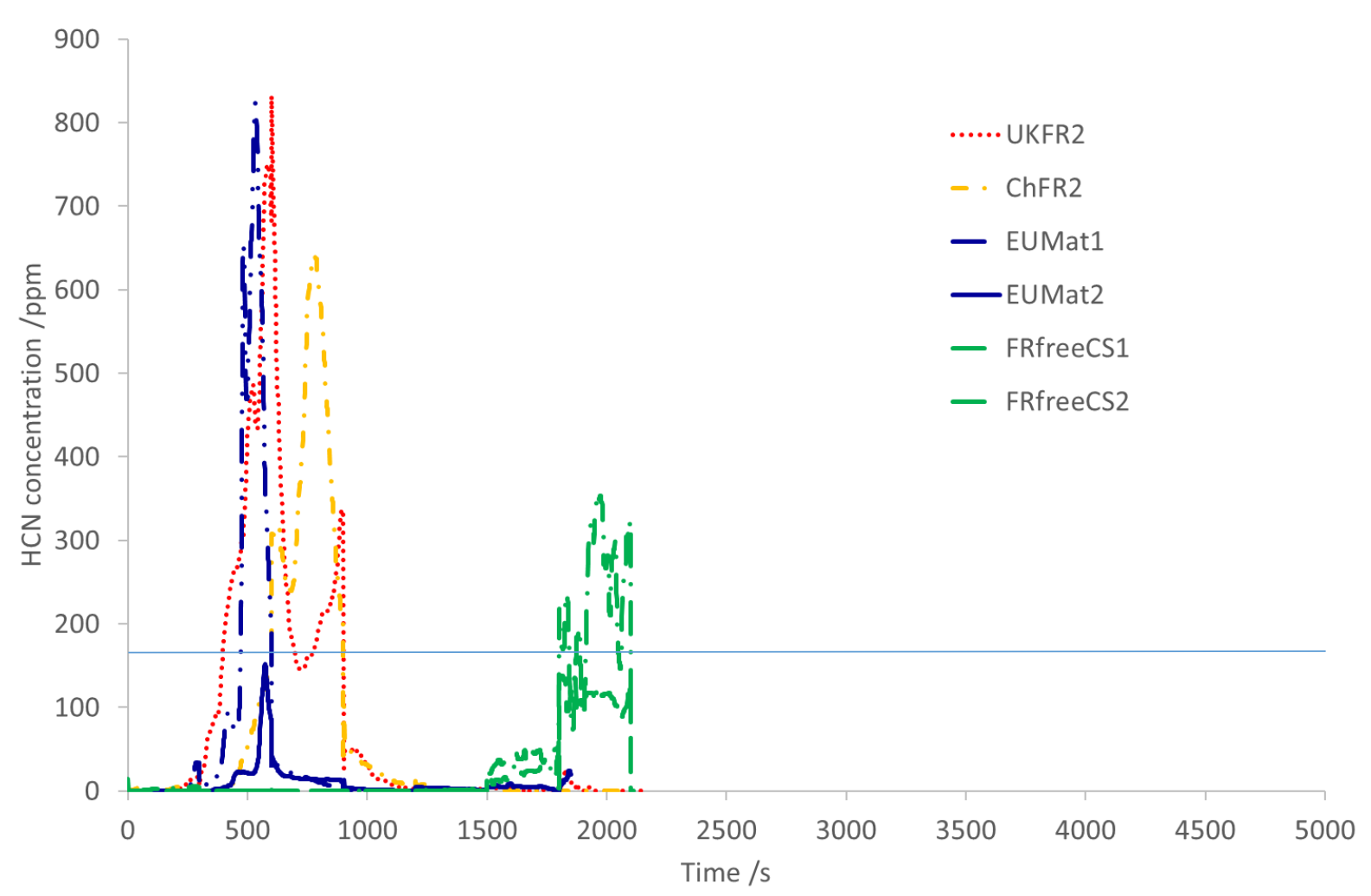

Figure 9 Hydrogen cyanide concentrations calculated from bubbler concentrations, and the relationship with CO concentration (showing LC 50 for 30 minutes exposure at 165 ppm from ISO 13344²3).

In order to relate gas concentrations to total yields of each toxicant, it is necessary to know the effluent flow leaving the test room. This was not measured directly in the tests, but calculated from the temperature profile and vent openings as described in the literature ${ }^{41}$. The heat from the fire causes the effluent to expand, making it less dense, which drives it through the outlet, causing fresh air to be drawn through the inlet. Such buoyant flows can be estimated from the temperature and vent sizes. The calculation is based on the assumption that the gas is split into two uniform layers an upper hot layer, and a cooler lower layer with densities $\rho_{\mathrm{h}}$ and $\rho_{\mathrm{c}}$ respectively.

The densities were calculated from the gas laws, assuming a molecular weight of both fresh air and smoke laden air of $28.95 \mathrm{~g} \mathrm{~mol}^{-1}$. This is reasonable, given the abundance of nitrogen in both air and 
effluent, and the replacement of $\mathrm{O}_{2}$ with $\mathrm{CO}, \mathrm{CO}_{2}$, water etc. The effluent velocity was estimated from

$v_{e f f}=\sqrt{2 g \frac{\left(\rho_{c}-\rho_{h}\right)}{\rho_{h}}} y$

Equation 3

where $y$ is the height of the vent above the cool-hot layer boundary from which the mass flow and volume flow of effluent were determined as a function of time for each test. This is based on the detailed guidance in ref. 41.

\section{Yields summary}

The yield data in Table 6 show the evolution of the two main asphyxiants, $\mathrm{CO}$ and $\mathrm{HCN}$ for the different furniture compositions. $\mathrm{CO}$ is present in the effluents from nearly all unwanted fires, whereas $\mathrm{HCN}$ is only detected where the fuel contains a significant amount of nitrogen.

With respect to the scale-up of yield data between the cone calorimeter (Table 4) and the large scale test (Table 6), UKFR and EUMat, $\mathrm{CO}$ and HCN yields are an order of magnitude greater in the sofa burn than in the cone calorimeter, showing the cone calorimeter does not replicate the behaviour of large scale under-ventilated fires. For the ChFR materials, the yields are similar in both scales, demonstrating that the cone calorimeter does replicate the effect of gas phase inhibition on the CO yield. For the FRfreeCS, superficially, there appears good agreement, but the burning behaviour was so different (flaming in cone calorimeter, mostly smouldering in the large-scale) such comparisons are unjustified.

Mass loss yields of $\mathrm{CO}$ and $\mathrm{HCN}$ presented in Table 6 are comparable and relate to other reports, such as $\mathrm{CO}$ and $\mathrm{HCN}$ yields from a burning polyurethane foam-fabric sofa of 0.015 and $0.004 \mathrm{~kg} / \mathrm{kg}$ pre-flashover, and 0.04 and 0.015 post-flashover, respectively ${ }^{42}$. 


\begin{tabular}{|l|l|l|l|l|l|}
\hline Sample & CO & HCN & CO Mass & HCN Mass & Volume of \\
& Total & Total & loss yield & loss yield & incapacitating \\
& Volume & Volume & $\mathbf{k g} / \mathbf{k g}$ & $\mathbf{k g} / \mathbf{k g}$ & effluent \\
& $/ \mathrm{m}^{3}$ & $/ \mathrm{m}^{3}$ & & & \\
& 1.366 & 0.082 & 0.171 & 0.010 & 105 after $1000 \mathrm{~s}$ \\
\hline UKFR2 & 0.922 & 0.064 & 0.142 & 0.009 & 79 after $1000 \mathrm{~s}$ \\
\hline ChFR2 & 1.354 & 0.037 & 0.157 & 0.004 & 94 after $1000 \mathrm{~s}$ \\
\hline EUMat1 & 0.647 & 0.007 & 0.075 & 0.001 & 57 after $1000 \mathrm{~s}$ \\
\hline EUMat2 & 1.027 & 0.007 & 0.063 & ND & 40 after $4000 \mathrm{~s}$ \\
\hline FRfreeCS1 & 1.027 & & & & \\
\hline FRfreeCS2 & 0.542 & ND & 0.032 & ND & 25 after $3800 \mathrm{~s}$ \\
\hline
\end{tabular}

\section{Estimates of incapacitation}

In addition to $\mathrm{CO}$ and $\mathrm{HCN}$ being responsible for almost all smoke inhalation deaths, at lower doses exposure to either or both of these gases results in incapacitation. Equation 1 has been used to estimate the effect of a fire effluent on exposed occupants.

A single UKFR sofa-bed, burning in a room (with the same ventilation as the shipping container, such as a partly open door), will produce an effluent capable of causing incapacitation (unconsciousness) when dispersed across a volume of $105 \mathrm{~m}^{3}$ (the size of a small house or apartment), $1000 \mathrm{~s}$ from ignition of the sofa-bed. Other burning mattress compositions will produce the incapacitating volumes shown in Table 6, assuming the effluent fills the volume uniformly.

This shows that the burning UKFR sofa-bed has the greatest capacity for incapacitation. This is based on the data from a single burn, and both the ChFR and EUMat sofa-beds also produce large volumes of incapacitating effluent, so this statement is not entirely conclusive. This arises from the effect of 
flame retardants increasing the yield the two most toxic products of incomplete combustion, $\mathrm{CO}$ and $\mathrm{HCN}$. Despite a higher overall temperature and greater burning rate, the smoke from the ChFR has a similar potential for incapacitation as the non-flame retardant EUMat sofa-bed. The burning FRfreeCS has the least potential for incapacitation, and this occurs much later, $4000 \mathrm{~s}$ after ignition, rather than just $1000 \mathrm{~s}$.

The contributions of $\mathrm{CO}$ and $\mathrm{HCN}$ towards incapacitation, calculated from Equation 1Error!

Reference source not found. are shown in Figure 10, assuming the effluent is dispersed within a volume of $100 \mathrm{~m}^{3}$. An FED equal to one would be expected to cause incapacitation to $50 \%$ of the exposed population. The non-linearity of FED to HCN (as FED $\propto[H C N]^{2.36}$ ) in Error! Reference source not found., and the arbitrary use of a $100 \mathrm{~m}^{3}$ volume makes the UKFR mattress disproportionately worse than the ChFR or EUMat1 sofa-beds, where Table 6 shows that the differences in HCN yields are not so large.

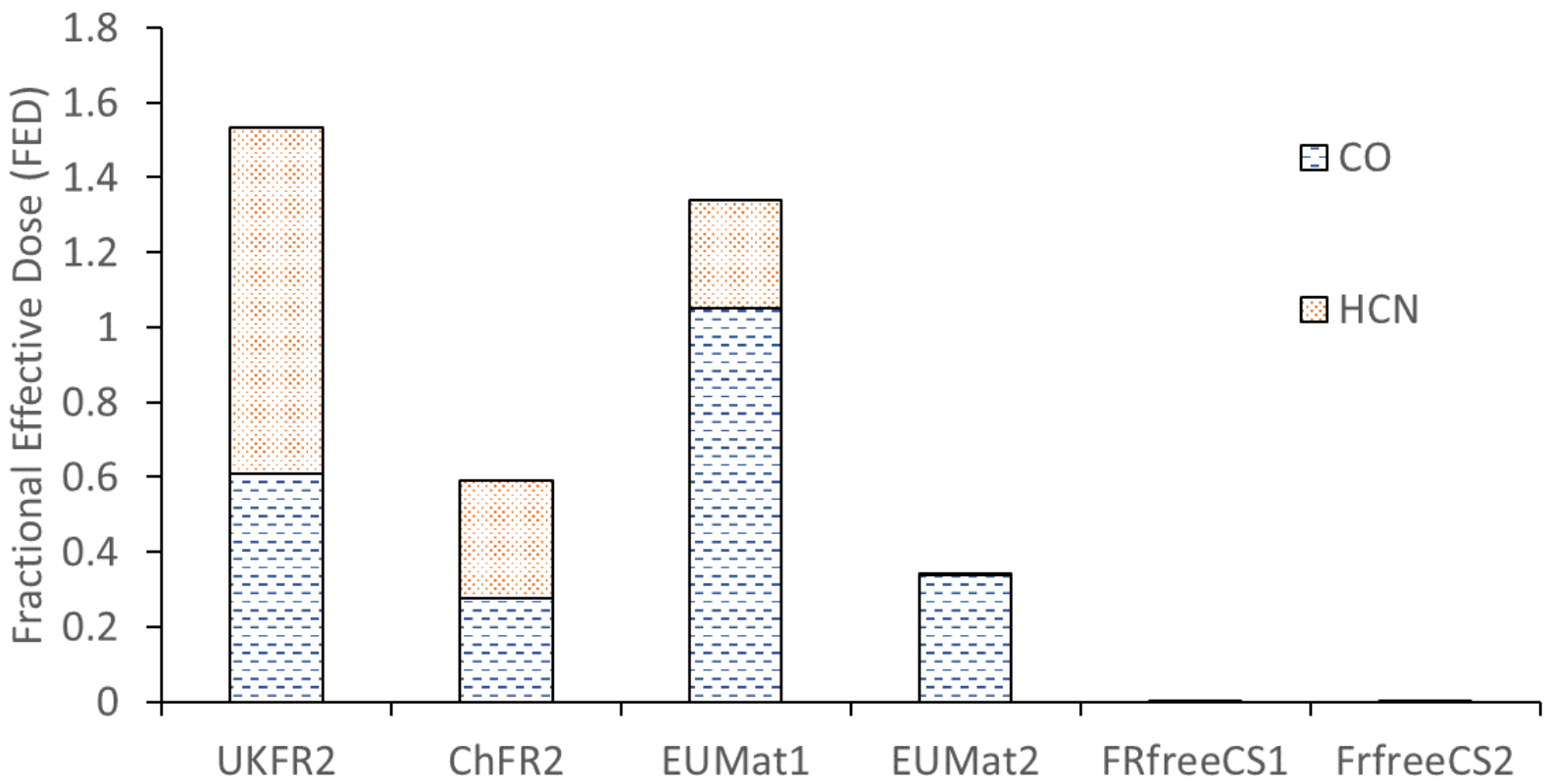

Figure 10 Fractional Effective Dose for incapacitation at $1000 \mathrm{~s}$, assuming a total volume of $500 \mathrm{~m}^{3}$. 


\section{Estimates of lethality}

HCN deprives the body of oxygen, and so stimulates respiration, increasing the uptake of toxicants, causing rapid unconsciousness ${ }^{43}$. At this point respiration falls back to normal levels, but since the unconscious victim can no longer escape they are likely to continue to inhale $\mathrm{CO}$ and $\mathrm{HCN}$ until death. Figure 11 shows the fractional effective dose for lethality for $30 \mathrm{~min}$ exposure to the effluent produced from burning each sofa-bed, when uniformly dispersed in a volume of $500 \mathrm{~m}^{3}$. The $30 \mathrm{~min}$ exposure presupposes the victims were unable to escape. In the case of the FRfreeCS mattress, this period of $30 \mathrm{~min}$ would not start until around $1 \mathrm{~h}$ after ignition. The greater contribution of HCN to the toxicity is evident for the two compositions containing flame retardants, although all three foams (UKFR, ChFR and EUMat) are likely to contain similar amounts of nitrogen.

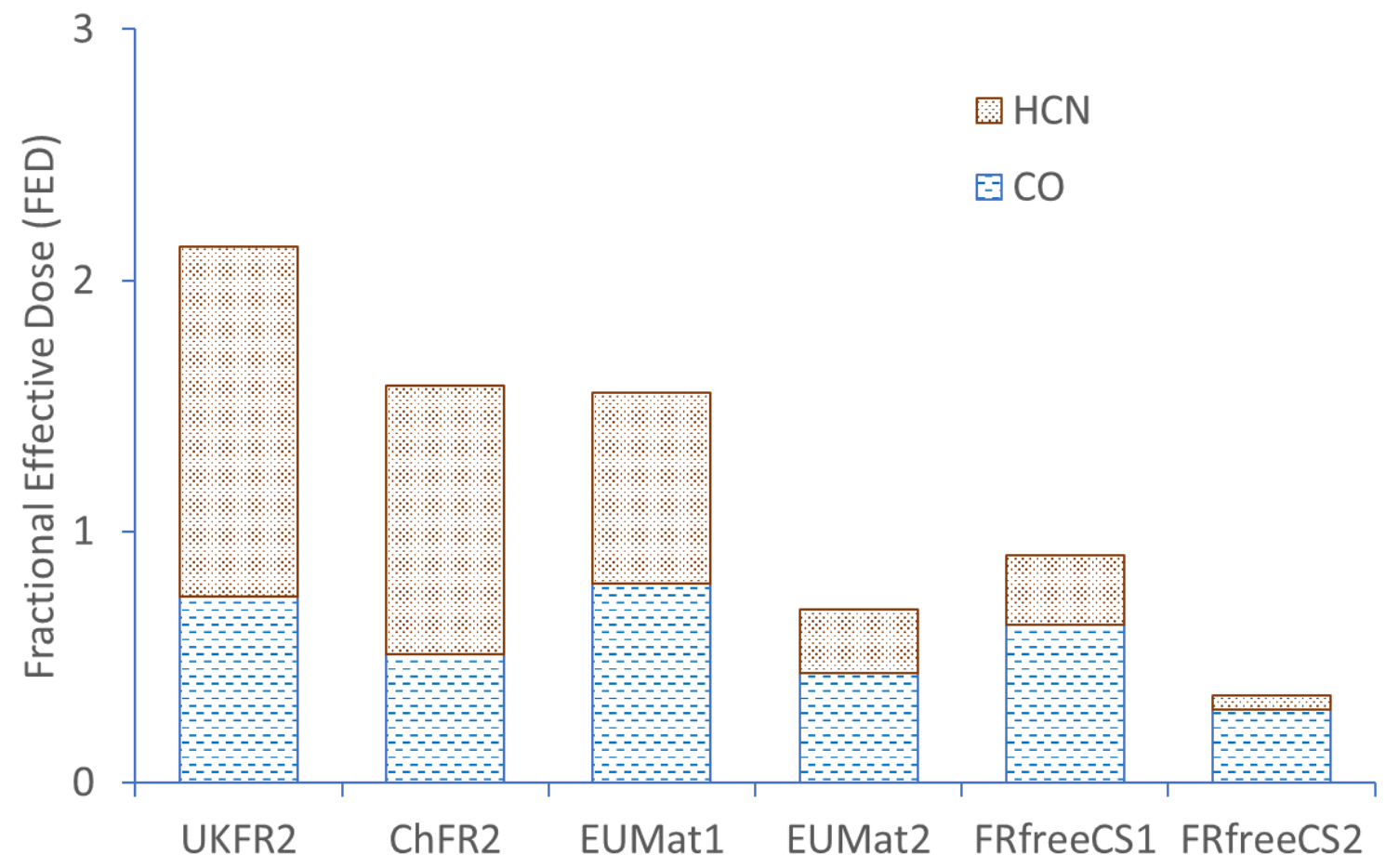

Figure 11 Fractional Effective Dose for lethality, assuming a $500 \mathrm{~m}^{3}$ volume and $30 \mathrm{~min}$ exposure 


\section{Conclusions}

The fire statistics in the introductory section shows that the claims made by flame retardant manufacturers, and repeated by the UK government, quantifying the effects of the furniture flammability regulations in reducing fire deaths are questionable. The time series data shows that smoke toxicity causes the majority of deaths and the majority of injuries from unwanted fires, and that these majorities were increasing. The fire death rate underlined the importance of upholstered furniture and bedding in fire fatalities, despite being a small proportion of the number of fires.

The aim of this study was to quantify the volume and toxicity of the effluents produce from burning sofas with different compositions, and particularly to see the effect of flame retardants on the fire growth rate and toxic product yields, since both these parameters would influence the hazard to life from fire. This aim has been partially me, and certainly highlights the need for further work in this important area. The study was based on four representative furniture formulations. It shows a significant hazard associated with the increased fire toxicity, resulting from incorporating flame retardants into furniture. Unfortunately, the data from the first two tests was not recorded, increasing the uncertainty of the results being representative of a more generalised trend. Clearly, further tests need to be carried out on a wider representative range of furniture in order to establish whether these observations can be generalised across the range of furniture products.

Despite the variation inherent in the fire tests, clear differences were observed in burning behaviour and toxic product yield of different compositions. However, for three of the four formulations, in the large scale test, there was very little difference in the time to ignition or fire growth rate, despite two of the three containing flame retardants. From the data in Figure 7 showing the peak temperature of the EUMat sofas was greater than any others, suggesting a larger peak of burning intensity. It is apparent that flame retardants affect both flammability and toxicity, although the differences are not consistent between scales. 
Table 7 summarises a qualitative rank order of each sofa-bed composition from the bench and large scale tests, from low to high hazard. It is important to note that the bench-scale data refer to wellventilated burning, while the large-scale data represent under-ventilated burning. The yields of CO and HCN presented in Table 4 and Table 6 are greater by factors of around 5 and 10 respectively, for the large-scale fires, particularly for the EUMat and FRFreeCS sofas, which did not contain gas phase flame retardants. From Table 7, it is clear that the best performance has been achieved on a largescale for the FRfreeCS mattress without any flame retardants. In upholstered furniture, flame retardants increase the toxicity of the smoke. The overall effect of the flame retardants (as seen in the large-scale tests) is to increase the fire hazard relative to the non-flame retarded EUMat. Based on the compositions used in this study, it is evident that meeting the UK furniture flammability regulations without the use of chemical flame retardants provides the lowest fire hazard, or the greatest level of fire safety.

Table 7 Fire performance of different compositions at different scales of test.

\begin{tabular}{|c|c|c|c|c|}
\hline \multicolumn{2}{|c|}{ Bench Scale } & \multicolumn{2}{|c|}{ Large Scale } & \\
\hline Flammability & Toxicity & Flammability & Toxicity & \\
\hline UKFR & FRfreeCS & FRfreeCS & FRfreeCS & Low hazard \\
\hline ChFR & EUMat & ChFR & EUMat & \\
\hline FRfreeCS & UKFR & UKFR & ChFR & \\
\hline EUMat & ChFR & EUMat & UKFR & High hazard \\
\hline
\end{tabular}

This work has shown that one of the most essential components of the fire hazard assessment from upholstered furniture and bedding has been disregarded in the furniture flammability regulations. It has been shown that fire toxicity is the main cause of death and injury in fires, and that upholstery 
and bedding fires cause a disproportionate number of fatalities, yet there is no requirement to assess the toxicity of burning domestic furniture. This has led to an over-reliance on chemical additives (flame retardants) to meet the UK's furniture flammability regulations. While we are unlikely to ever have robust data showing how effective flame retardants are in suppressing ignition, it is evident that once ignition occurs, the presence of flame retardants has little effect on the fire growth rate, but does have an adverse effect on the smoke toxicity.

However, further work is needed to ensure the results are representative of the situation across the UK. It is important to note that currently only samples of new furniture are tested and required to meet the furniture flammability regulations. All the sociological indicators show that fire deaths predominate in the poorest sections of society, where sofas are likely to be 10 or more years old. Reports in the literature show that the UK has the highest levels of flame retardants in household dust in the world ${ }^{44}$ which are probably released from upholstered furniture and bedding during its lifetime, negating any potential fire safety benefit from the furniture flammability regulations, while causing problems of endocrine disruption (such as developmental disorders, difficulty in becoming pregnant, and obesity) from inhalation or ingestion of the contaminated dust.

\section{Acknowledgements}

One of us (RB) would like to thank Greater Manchester Fire and Rescue Service for provision of a studentship. One of us (RGW) would like to thank West Midlands Fire Service for provision of a studentship. We would all like to thank Mark Dowen of Cottonsafe Natural Mattress for provision of samples, help and advice, and Lancashire Fire and Rescue Service for provision of test facilities at their Washington Hall training centre.

1 Fire statistics monitor: April 2015-March 2016, UK Government, Home Office, https://www.gov.uk/government/statistics/fire-statistics-monitor-april-2015-tomarch-2016 and preceding editions.

2 Woolley, W.D., Raftery, M.M., Smoke and toxicity hazards of plastics in fires, (1975) Journal of Hazardous Materials, 1 (3), pp. 215-222.

3 Alarie, Y., Toxicity of fire smoke, (2002) Critical Reviews in Toxicology, 32 (4), pp. 259-289. 
4 BS 5852:2006 Methods of test for assessment of the ignitability of upholstered seating by smouldering and flaming ignition sources.

5 A Emsley, L Lim, G Stevens, P Williams, International Fire Statistics and the Potential Benefits of Fire Counter-Measures, for European Flame Retardant Association (EFRA) PRC/92/2005/EFRA, May 2005

6 A statistical report to investigate the effectiveness of the Furniture and Furnishings (Fire) (Safety) Regulations, 1988, Greenstreet Berman Ltd, for the UK's Department for Business, Innovation and Skills, December 2009

7 Hull, T.R., Law, R.J., Bergman, Å., Environmental Drivers for Replacement of Halogenated Flame Retardants, (2014) Polymer Green Flame Retardants, pp. 119-179.

8 Prior to 1994: http://www.stats.govt.nz/browse for stats/snapshots-of-nz/digital-yearbookcollection.aspx. 1994-2000: http://www.civil.canterbury.ac.nz/fire/pdfreports/CWong.pdf. 2000 onwards http://www.fire.org.nz/About-Us/Facts-and-Figures/Pages/Statistics-Data-Fields.html

9 Arcadis EBRC, Report for European Commission (DG Health and Consumers) - Evaluation of data on flame retardants in consumer products - Final report 17.020200/09/549040, Brussels, 2011. http://ec.europa.eu/consumers/safety/news/flame retardant substances study en.pdf

10 Walker R G, PhD Thesis, University of Central Lancashire, UK, 2017.

11 De Wit, C.A., An overview of brominated flame retardants in the environment, (2002) Chemosphere, 46 (5), pp. 583-624.

12 Hites, R.A., Polybrominated Diphenyl Ethers in the Environment and in People: A Meta-Analysis of Concentrations, (2004) Environmental Science and Technology, 38 (4), pp. 945-956.

13 Darnerud, P.O., Eriksen, G.S., Jóhannesson, T., Larsen, P.B., Viluksela, M., Polybrominated diphenyl ethers: Occurence, dietary exposure, and toxicology, (2001) Environmental Health Perspectives, 109 (SUPPL. 1), pp. 49-68.

14 Darnerud, P.O. Toxic effects of brominated flame retardants in man and in wildlife, (2003) Environment International, 29 (6), pp. 841-853.

15 Law, R.J., Allchin, C.R., de Boer, J., Covaci, A., Herzke, D., Lepom, P., Morris, S., Tronczynski, J., de Wit, C.A. Levels and trends of brominated flame retardants in the European environment, (2006) Chemosphere, 64 (2), pp. 187-208.

16 Covaci, A., Harrad, S., Abdallah, M.A.-E., Ali, N., Law, R.J., Herzke, D., de Wit, C.A. Novel brominated flame retardants: A review of their analysis, environmental fate and behaviour, (2011) Environment International, 37 (2), pp. 532-556.

17 van der Veen, I., de Boer, J. Phosphorus flame retardants: Properties, production, environmental occurrence, toxicity and analysis, (2012) Chemosphere, 88 (10), pp. 1119-1153.

18 Shaw S D, Blum A, Weber R, Kannan K, Rich D, Lucas D, Koshland C P, Dobraca D, Hanson S, Birnbaum L S. Halogenated flame retardants: Do the fire safety benefits justify the risks? Rev Environ Health 2010;25:261-305.

19 Brommer, S., Harrad, S., Sources and human exposure implications of concentrations of organophosphate flame retardants in dust from UK cars, classrooms, living rooms, and offices, (2015) Environment International, 83, pp. 202-207.

20 Stubbings, W.A., Drage, D.S., Harrad, S., Chlorinated organophosphate and "legacy" brominated flame retardants in UK waste soft furnishings: A preliminary study, (2016) Emerging Contaminants, 2 (4), pp. 185-190.

21 Babrauskas, V., Levin, B.C., Gann, R.G., Paabo, M., Harris Jr., R.H., Peacock, R.D., Yusa, S., Toxic potency measurement for fire hazard analysis, (1992) Fire Technology, 28 (2), pp. 163-167.

22 Purser, D.A., The evolution of toxic effluents in fires and the assessment of toxic hazard, (1992) Toxicology Letters, 64-65 (C), pp. 247-255.

23 ISO 13344:2015, Estimation of the lethal toxic potency of fire effluents.

24 ISO 13571:2012, Life threat from fires - Guidance on the estimation of time available for escape using fire data. 
25 Hull, T.R., Stec, A.A., Paul, K.T., Hydrogen chloride in fires, (2008) Fire Safety Science, pp. 665676.

26 Kaczorek, K., Stec, A.A., Hull, T.R., Carbon monoxide generation in fires: Effect of temperature on halogenated and aromatic fuels, (2011) Fire Safety Science, pp. 253-263.

27 Hull, T.R., Stec, A.A., Lebek, K., and Price, D., (2007) Factors Affecting the Combustion toxicity of Polymeric Materials, Polymer Degradation and Stability, 92:2239-2246.

28 Molyneux, S., Hull, T.R., Stec, A.A. (2014) The Effect of Gas Phase Flame Retardants on Fire Effluent Toxicity, Polymer Degradation and Stability 106:36-46.

29 Stec, A.A., Hull, T.R., Lebek, K., Purser, J.A., Purser, D.A., The effect of temperature and ventilation condition on the toxic product yields from burning polymers, (2008) Fire and Materials, 32 (1), pp. 49-60.

30 Stec, A.A., Hull, T.R., Torero, J.L., Carvel, R., Rein, G., Bourbigot, S., Samym, F., Camino, G., Fina, A., Nazare, S., Delichatsios, M., Effects of fire retardants and nanofillers on the fire toxicity, (2009) ACS Symposium Series, 1013, pp. 342-366.

31 Blomqvist, P., and Lonnermark, A., Fire and Materials. 25, 71-81, (2001).

32 Andersson B., Markert F., and Holmstedt G., Fire Safety Journal, 40, 439-465, (2005).

33 ISO 5660-1:2015 Reaction-to-fire tests - Heat release, smoke production and mass loss rate Part 1: Heat release rate (cone calorimeter method) and smoke production rate (dynamic measurement)

34 Molyneux, S.A., Stec, A.A., Hull, T.R., The correlation between carbon monoxide and hydrogen cyanide in fire effluents of flame retarded polymers, (2014) Fire Safety Science, 11, pp. 389-403.

35 Wang, Z., Jia, F., Galea, E.R., A generalized relationship between the normalized yields of carbon monoxide and hydrogen cyanide, (2011) Fire and Materials, 35 (8), pp. 577-591.

36 Purser, D., Purser, J., HCN yields and fate of fuel nitrogen for materials under different combustion conditions in the ISO 19700 tube furnace and large-scale fires, (2008) Fire Safety Science, pp. 1117-1128.

37 https://cottonsafenaturalmattress.co.uk/natural-mattresses/bond-3-seater-futon-sofa-bed/ accessed 3rd Dec 2017.

38 ISO 19701:2013 Methods for sampling and analysis of fire effluents, ISO, Geneva.

39 Stec, A.A., Molyneux, S., Crewe, R.J., Sampling and Analysis of Toxic Gases from Large-Scale Fire Experiments, submitted to Fire Safety Journal, 2017.

40 Schnipper, A., Smith-Hansen, L., Thomsen, E.S., Reduced combustion efficiency of chlorinated compounds, resulting in higher yields of carbon monoxide, (1995) Fire and Materials, 19 (2), pp. 61-64.

41 Tanaka, T. Vent flows, (2016) SFPE Handbook of Fire Protection Engineering, Fifth Edition, pp. 455-485.

42 Gann, R. G., Averill, J. D., Johnsson, E. L., Nyden, M. R., Peacock, R. D., Fire effluent component yields from room-scale fire tests, Fire and Materials, 34, 285-314, 2010.

43 Stec A and Hull R (editors), Fire Toxicity, Woodhead/Elsevier, Cambridge, UK, 2010

44 Kuang, J., Ma, Y., Harrad, S., Concentrations of "legacy" and novel brominated flame retardants in matched samples of UK kitchen and living room/bedroom dust, (2016) Chemosphere, 149, 224-230. 